\title{
O6 IMMUNOTHERAPY AND IMMUNOMODULATION
}

06.001 - PROTECTIVE EFFECT OF RECOMBINANT AND PLANT-DERIVED $\mathrm{KM}^{+}$LECTIN ON EXPERIMENTAL PARACOCCIDIOIDES BRASILIENSIS INFECTION IN MICE.

Coltri, K. C. ${ }^{1}$; Panunto-Castelo, A. ${ }^{2}$; Oliveira, L. L. ${ }^{3}$; Goldman, M. H. ${ }^{4}$; Roque-Barreira, M. C, ${ }^{1,2,3,5}$ FMRP - USP - Biologia Celular e Molecular e Bioagentes Patogenicos; ${ }^{4}$ FFCLRP - USP Departamento de Biologia

Introduction and Objectives: Our group have previously shown that $\mathrm{KM}^{+}$, a mannosebinding lectin extracted from jack-fruit seeds (Artocarpus integrifolia), induced IL-12 production either in vitro or in vivo, and therefore was able to switch the cytokine profile from Th2 (IL-4) to Th1 (IFN- $\gamma$ ), leading to the development of a protective Th1-type polarized response against Leishmania major in BALB/c mice infection model (Glycobiology. 11:1035$1042,2001)$. Since resistance to $P$. brasiliensis infection correlates with efficient Th1 immune response, we aimed to evaluate the interference of $\mathrm{jfKM}^{+}\left(\mathrm{KM}^{+}\right.$extracted from jack fruit seeds) administration as well as its recombinant counterpart $\left(\mathrm{rKM}^{+}\right)$in the course of experimental paracoccidioidomycosis (PCM). Methods and Results: BALB/c mice were divided into two experimental groups, according to the period of $\mathrm{KM}^{+}(0.5 \mu \mathrm{g})$ subcutaneous administration: group I was injected with $\mathrm{fKMM}^{+} / \mathrm{rKM}^{+} 10$ and 3 days before the intravenous challenge with P. brasiliensis ( $1 \times 10^{6}$ yeasts of $\mathrm{Pb} 18$ isolate), whereas group II was injected 10 days after the challenge. Control groups received PBS instead of $\mathrm{jfKM}^{+} / \mathrm{rKM}^{+}$or yeasts. The animals were killed 14 and 30 days postinfection and several parameters were analyzed. Mice from groups I and II, presented $86 \%$ less colony forming units (CFU) in lungs than the non-treated control group. Moreover, histopathology of lung sections from these groups of mice (I and II) revealed total absence or very few organized granulomas. Nevertheless, the non-treated control group presented large and confluent granulomas involving extensive areas of the lungs, with an inflammatory cellular infiltration and numerous budding yeast cells, reflecting the CFU data. When we compared the pulmonary cytokines produced by groups I and II with those produced by the non-treated control group we observed that lung homogenates derived from both groups revealed a Th1 bias, with high NO production and high levels of proinflamatory cytokines TNF- $\alpha$, IL12 and IFN- $\gamma$, whereas the non-treated control group, by contrast, presented substantial release of Th2-type cytokines such as IL-4 and IL-10. Conclusion: Taken together, our observations strengthen the view that $\mathrm{jfKM}^{+}$, as well as $\mathrm{rKM}^{+}$administered either before or after challenge, exerts a protective effect against $P$. brasiliensis infection, with a direct beneficial effect on the lesions severity. Additional investigations are in progress in order to clarify the whole spectrum of $\mathrm{KM}^{+}$interference on experimental PCM. Financial support: FAPESP, CAPES and CNPq.

\subsection{2 - SYNERGIC EFFECT OF P10 IMMUNIZATION AND CHEMOTHERAPY} IN MICE WITH ESTABLISHED PULMONARY PARACOCCIDIOIDOMYCOSIS Marques, A. F. ${ }^{1}$; Da Silva, M. B. ${ }^{2}$; Buissa Filho, R. ${ }^{3}$; Juliano, M. A. P.'; Travassos, L. R. ${ }^{5}$; Taborda, C. P. ${ }^{6}$

1,2,3,6Institute of Biomedical Sciences, University of São Paulo, São Paulo, Brazil - Department of Microbiology; ${ }^{4}$ Federal University of São Paulo, São Paulo, Brazil - Departament of Biophysics ; ${ }^{5}$ Federal University of São Paulo, São Paulo, Brazil - Department of Microbiology, Immunology and Parasitology

Background: Paracoccidioidomycosis (PCM) is a systemic granulomatous disease caused by Paracoccidioides brasiliensis. It is widespread in South and Central America with approximately 10 million people possibly infected with this fungus. All patients with progressive PCM require antifungal treatment chiefly based on sulfamethoxazoletrimethoprim, amphothericin B and azole-derived drugs. A long-term follow-up is important in all cases because of the high incidence of relapsing disease. The 15 -amino-acid peptide (P10) from the major 43-kDa diagnostic antigen of $P$. brasiliensis is protective against experimental infection in mice. Presently, we analyzed the synergic effect of P10 immunization and chemotherapy in mice with established pulmonary infection. Methods: Mice were infected intratracheally with $3 \times 10^{5}$ yeast cells of virulent $P$. brasiliensis $(\mathrm{Pb} 18)$ and were treated 30 days after infection with the antifungal drug (sulphametoxazole-trimethoprim, ketoconazole, itraconazole, fluconazole and amphotericin B) for 30 days in association with peptide P10 immunization. Control groups of infected mice were either treated with drugs, immunized with peptide only, or did not receive any treatment. Groups of mice were sacrificed 60 and 120 days after infection and colony forming units (CFU) from lung, liver and spleen were counted. Results: A synergic effect of chemotherapy and P10 immunization was observed with all drugs tested; a significant reduction of CFU in the lungs of mice was observed. Antifungal drugs tested separately or P10 immunization alone reduced significantly the lung CFUs but not as efficiently as with the association protocol. Sulphametoxazoletrimethoprim treatment resulted in reactivation of the disease at the end of chemotherapy but not in association with P10 in which case a most effective control of the disease was obtained. Discussion: Our results showed that: (I) the association of P10 immunization and itraconazole, fluconazole, or sulphametoxazole-trimethoprim treatment was more effective than the separate treatment with drugs or immunization; (II) the immunization with P10 (and other peptides derived from the gp43 and presented by human HLA-DR molecules) in association with chemotherapy, should be construed as a potential adjuvant therapy of human paracoccidioidomycosis. Financial support: Supported by FAPESP
06.003 - VACCINATION WITH HEAT SHOCK PROTEIN 60 INDUCES T CELL MEDIATED RESPONSE AND IS PROTECTIVE AGAINST EXPERIMENTAL PARACOCCIDIOIDES BRASILIENSIS PULMONARY INFECTION Soares, R. B. A. ${ }^{\prime}$; Gomez, F. J.'; Cunha-Passos, D. A. ${ }^{3}$; Bao, S. N. ${ }^{4}$; Soares, C. M. A. ${ }^{5}$; Deepe Jr., G. S. ${ }^{6}$

${ }_{1,3,5} U F G$ - Department of Biochemistry and Molecular Biology; ${ }^{2,6}$ University of Cincinnati, Ohio, USA, 45267-0560 - College of Medicine, Division of Infectious Diseases; ${ }^{4}$ UnB - Department of Cell Biology

Introduction and Objectives: Paracoccidioides brasiliensis is a human pathogenic fungus that constitutes a major medical problem in Latin America. The infection is acquired by either inhalation or percutaneous inoculation of mycelia forms. At tissue temperatures, the pathogen transforms into a yeast form that parasitizes the intracellular compartment of macrophages, eliciting chronic, granulomatous inflammation. Yeasts are responsible for most of the clinical manifestations of PCM. T cell responses are critical for the containment of the parasite. Little is known about the antigens involved in T cell responses against this pathogen. Heat shock protein 60 (HSP60), isolated from intracellular fungal, protozoa and bacterial pathogens have been found to elicit protective immunity in models of infection. In this study we examined PbHSP60 as a target of T cell mediated immune response to $P$. brasiliensis and delineated its activity as a vaccine in experimental PCM during the inductive and expressive phases of PbHSP60-immune responses. Methods: Groups of BALB/c mice were immunized by two S.C. injections of $10 \mathrm{mg}$ recombinant PbHSP60 or BSA (as a control). Infection was initiated two weeks later by intranasal inoculation of either $10^{6}$ or $10^{7}$ P. brasiliensis yeast cells. In some experiments, $\mathrm{CD} 4^{+}, \mathrm{CD} 8^{+}$or both subset of $\mathrm{T}$ cells were depleted by I.P. injection of monoclonal antibodies before or after immunization with $P b$ HSP60. Severity of infection was measured by quantification of fungal burden in quantitative lung cultures. Results: Vaccination with 10mg of PbHSP60 protected mice against of $P$. brasiliensis infection. Elimination of $\mathrm{CD}^{+}{ }^{+}$cells abolished the protection conferred by PbHSP60 during the inductive and expressive phase of PbHSP60 immune responses. Conclusions: $P b H S P 60$ plays a role in protection against experimental PCM by eliciting a CD4 mediated immune responses. The cytokine profile and the tissue distribution of HSP60 specific CD4 cells is under investigation. Financial support: CNPq

\subsection{4 - EFFECT OF MONOCLONAL ANTIBODIES AGAINST THE MAJOR} DIAGNOSTIC ANTIGEN OF P. BRASILIENSIS ON THE REDUCTION OF LUNG INFECTION

Buissa Filho, R. ; Marques, A. F. ${ }^{2}$; Da Silva, M. B. ${ }^{3}$; Puccia, R. ${ }^{4}$; Travassos, L. R. ${ }^{5}$; Taborda, C. P $^{6}$

${ }_{1,2,3,6}$ University of São Paulo, São Paulo, Brazil - Department of Microbiology; ${ }^{4,5}$ Federal University of São Paulo, São Paulo, Brazil - Department of Microbiology, Immunology and Parasitology

Background: Paracoccidioidomycosis (PCM) is a systemic granulomatous disease caused by Paracoccidioides brasiliensis. It is widespread in South and Central America with approximately 10 million people possibly infected with this fungus. The $43 \mathrm{kDa}$ glycoprotein (gp43) is the major diagnostic antigen of PCM, secreted exocellularly by the infective yeast phase, and recognized by virtually all sera from infected patients using different serological methods. The biological function of antibodies in PCM is unknown and usually high titers are associated with the acute form and bad prognosis. In this study, we evaluated the influence of several monoclonal antibodies (mAb) against gp43 in mice intratracheally infected with a virulent isolate of $\mathrm{Pb} 18$. Methods: We have analyzed the effect of four anti-gp43 IgG2a mAbs (32H, 19G, 17D and 10D) and two IgG2b mAbs (3E and 21F). As a control, an irrelevant $\mathrm{mAb}(\mathrm{A} 4)$ was used. Twenty four hours before the mice were intratracheally infected with $3 \times 10^{5}$ yeast cells of $\mathrm{Pb} 18,1 \mathrm{mg}$ of $\mathrm{mAbs}$ was injected intraperitoneally per animal. Groups of mice were sacrificed 15 and 30 days after the infection and colony forming units (CFU) from lungs were counted. Results: Significant reduction in the lung CFUs was observed after 15 days with all mAbs tested with the exception of mAb 32H (IgG2a). However, after 30 days of infection, mAbs $19 \mathrm{G}$ and $10 \mathrm{D}$ (IgG 2a) and $3 \mathrm{E}(\mathrm{IgG} 2 \mathrm{~b})$ were able to control the disease unlike mAbs $32 \mathrm{H}$ and $17 \mathrm{D}$ (IgG2a) and $21 \mathrm{~F}$ (IgG2b) that caused a very significant increase in the number of lung CFUs. Discussion: Our results showed that some mAbs against gp43 were able to reduce the CFUs from lungs of infected mice whereas others did not. Even today, the relationship between Ag-specific antibody protection remains poorly understood in the majority of fungal dimorphic pathogens causing systemic mycoses. Presently, this study has been extended to P. brasiliensis. Data suggest that specific Ab responses can have a role in the immunological protection against PCM. Financial support: FAPESP. 
06.005 - DNA VACCINE AGAINST PARACOCCIDIODOMYCOSIS

Ribeiro Melo, A. ${ }^{1}$; Bocca, A. L. ${ }^{2}$; Tavares, A. H. ${ }^{3}$; Coelho-Castelo, A. A. M. ${ }^{4}$; Silva, C. L. ${ }^{5}$; Felipe, M. S. S. ${ }^{6}$

${ }^{1}$ UnB - Biologia Molecular; ${ }^{2,3}$ UnB - Biologia Celular; ${ }^{4}$ FMRP - USP - Bioquímica e Imunologia; ${ }^{5}$ Centre of Tuberculosis Research - Biochemistry and Immunology; ${ }^{6} \mathrm{UnB}$ - Departament of Cell Biology

Introduction and Objectives : The use of DNA vaccine, in experimental stage and clinical tests can be a major tool to prevent several infections and eliminate them if they are already established. Previous works demonstrated that a DNA vaccine codifying the Mycobacterium leprae HSP65 gene cloned into pcDNA3 can prevent infection by Mycobacterium tuberculosis and have a pronounced therapeutic action. In this context, the aims of this study are to test this vaccine in mice infected with Paracoccidioides brasiliensis $(\mathrm{Pb})$ and then to modulate, through the utilization of the DNA-hsp65 vaccine, the cellular immune response of mice experimentally infected with $\mathrm{Pb}$. Methods and Results : BALB/ $\mathrm{C}$ mice were vaccinated three times at two-week intervals with the control vector, pcDNA3 -

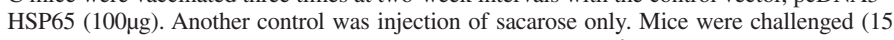
days after the third immunization) by intravenous route with $10^{6}$ cells of $\mathrm{Pb} 18$ and sacrificed after 60 days. Lung fungal burden were counted as colony forming units (C). We found that vaccination with HSP65-DNA caused CFU decline in lungs compared to both controls. Histological analyses confirmed these results. Spleen cells proliferation assays, using as stimuli concanavalin A, showed similar response to non-infected mice. Citokine produced in plasm and by spleen cells from vaccinated mice are currently being evaluated. Conclusion: Immunization by intramuscular DNA vaccine protects mice against infection by the virulent $\mathrm{Pb}$. Therapeutic effects of DNA vaccination against paracoccidiodomycosis are being investigated. New experiments are being carried out using the pVAX 200-DEST vector, specifically designed for DNA vaccines. Financial support: CNPq, MCT and FAP-DF.
06.006 - DEVELOPMENT OF A RADIOATTENUATED PARACOCCIDIOIDES BRASILIENSIS VACCINE

Demicheli, M. C. ${ }^{1}$; Andrade, A. S. R ${ }^{2}$; Reis, B. S. ${ }^{3}$; Goes, A. M. ${ }^{4}$; Martins, E. M. N. ${ }^{5}$

${ }^{I}$ CDTN - Radiobiologia; ${ }^{2,5}$ CDTN - Radiobiologia; ${ }^{3,4}$ UFMG - Bioquímica e Imunologia

Paracoccidioides brasiliensis is the agent of paracoccidioidomycosis, the most systemic mycosis in Latin America. To date, there is no effective vaccine. Vaccines can be developed using attenuated pathogens and the ionizing radiation has been used for this purpose since irradiated pathogens frequently lost its virulence or reproductive ability, but retains its morphology and metabolism. The aim of this work was to attenuate the yeast form of $P$ brasiliensis by gamma irradiation for further studies on vaccine research. P. brasiliensis, strain $\mathrm{Pb}-18$, were cultured in $\mathrm{BHI}$ at $37^{\circ} \mathrm{C}$. Five-day cultures were irradiated at doses between 0.5 and $10 \mathrm{kGy}$. After each dose the fungal cells were suspended in PBS, counted, plated and after 7 days the colony forming units (CFU) counted. The viability of the irradiated cells was measured using the dye Janus Green and the protein synthesis by incorporation of $\mathrm{L}^{-35} \mathrm{~S}$ methionine. The proteins secretion was evaluated incubating the cells in a medium without macromolecules and the protein concentration estimated in the supernatant. The comparison between the antigenic profile of irradiated and control yeast was made by western blot. The virulence of the irradiated yeast was analyzed by the inoculation in BALBc mice. After 30 days the organs were removed, homogenized and the suspensions plated. At $6.5 \mathrm{kGy}$ the yeast lost the reproductive capacity, since no colony forming units were detected in the plating experiment. The viability and the incorporation of $\mathrm{L}^{-35} \mathrm{~S}$ methionine were the same in contro and up to $6,5 \mathrm{kGy}$ irradiated cells, but $6.5 \mathrm{kGy}$ irradiated yeast secreted $40 \%$ less proteins. The western blot profile was clearly similar in control and $6.5 \mathrm{kGy}$ irradiated yeast indicating that the irradiated yeast retained the expression of the antigens present in the wild yeast. No CFU was recovery from the tissues of the mice infected with $6.5 \mathrm{kGy}$ radioattenuated yeast. We concluded that for $P$. brasiliensis yeast was possible find a dose in which the pathogen lost its reproductive ability and virulence, while retains its viability, metabolic activity and the antigenic profile. Financial support: CDTN/CNEN 